\title{
Ion - particle interactions during particle formation and growth at a coniferous forest site in central Europe
}

\author{
S. G. Gonser ${ }^{1}$, F. Klein ${ }^{1, *}$, W. Birmili ${ }^{2}$, J. Größ ${ }^{2}$, M. Kulmala ${ }^{3}$, H. E. Manninen ${ }^{3}$, A. Wiedensohler ${ }^{2}$, and A. Held ${ }^{1}$ \\ ${ }^{1}$ University of Bayreuth, BayCEER, Atmospheric Chemistry, 95448 Bayreuth, Germany \\ ${ }^{2}$ Leibniz Institute for Tropospheric Research, 04318 Leipzig, Germany \\ ${ }^{3}$ Department of Physics, University of Helsinki, 00014 Helsinki, Finland \\ *now at: Gasphase and Aerosol Chemistry Group, Paul Scherrer Institute, 5232 Villigen, Switzerland
}

Correspondence to: S. G. Gonser (stefan.gonser@uni-bayreuth.de)

Received: 13 December 2013 - Published in Atmos. Chem. Phys. Discuss.: 6 January 2014

Revised: 1 September 2014 - Accepted: 3 September 2014 - Published: 9 October 2014

\begin{abstract}
In this work, we examined the interaction of ions and neutral particles during atmospheric new particle formation (NPF) events. The analysis is based on simultaneous field measurements of atmospheric ions and total particles using a neutral cluster and air ion spectrometer (NAIS) across the diameter range $2-25 \mathrm{~nm}$. The Waldstein research site is located in a spruce forest in NE Bavaria, Southern Germany, known for enhanced radon concentrations, presumably leading to elevated ionization rates. Our observations show that the occurrence of the ion nucleation mode preceded that of the total particle nucleation mode during all analyzed NPF events. The time difference between the appearance of $2 \mathrm{~nm}$ ions and $2 \mathrm{~nm}$ total particles was typically about 20 to $30 \mathrm{~min}$. A cross correlation analysis showed a rapid decrease of the time difference between the ion and total modes during the growth process. Eventually, this time delay vanished when both ions and total particles did grow to larger diameters. Considering the growth rates of ions and total particles separately, total particles exhibited enhanced growth rates at diameters below $15 \mathrm{~nm}$. This observation cannot be explained by condensation or coagulation, because these processes would act more efficiently on charged particles compared to neutral particles. To explain our observations, we propose a mechanism including recombination and attachment of continuously present cluster ions with the ion nucleation mode and the neutral nucleation mode, respectively.
\end{abstract}

\section{Introduction}

Tropospheric new particle formation (NPF) is a worldwide phenomenon (Kulmala et al., 2004a; Kulmala and Kerminen, 2008) contributing to the global particle number and total amount of cloud condensation nuclei (Makkonen et al., 2012; Merikanto et al., 2009; Spracklen et al., 2006). The first step leading to NPF is thought to be the formation of stable clusters from precursor gas phase components as sulfuric acid, amines, ammonia and organic vapors (Almeida et al., 2013; Kulmala et al., 2013; Schobesberger et al., 2013). The formation of stable clusters happens in the mobility diameter $\left(D_{\mathrm{m}}\right)$ range between 1 to $2 \mathrm{~nm}$. Once formed, the stable clusters are activated and experience rapid growth (Kulmala et al., 2013). Atmospheric ions are very likely to play a considerable role in atmospheric nucleation processes, as ions reduce the critical cluster size and facilitate cluster activation (e.g., Enghoff and Svensmark, 2008; Winkler et al., 2008; Yue and Chan, 1979). In fact, comprehensive field measurements of NPF events at different locations in Europe showed an earlier formation of charged particles compared to total particles (neutral + charged particles; Manninen et al., 2010). Furthermore, the charging state of aerosol particles during NPF was observed to be frequently overcharged (Gagné et al., 2010; Iida et al., 2006; Laakso et al., 2007). The ratio of charged particle concentrations to neutral particle concentrations in a defined diameter interval is defined as the charged fraction. In a bipolar ion environment, the size-dependent charged fraction of an aerosol will eventually reach an equilibrium charging state due to ion-particle interactions (Fuchs, 1963; 
Wiedensohler, 1988). When the charged fraction is elevated in comparison to the equilibrium charged fraction, an aerosol is defined to be in an overcharged charging state.

When ions are involved in the nucleation process, two terms are usually used: ion-induced nucleation (IIN: e.g., Manninen et al., 2010) and ion-mediated nucleation (IMN; e.g., Yu and Turco, 2000). IIN denotes the formation of particles from small ionic clusters, preserving the charge during growth process. Additionally, when interactions of ions and particles are taken into account the term IMN is used. Hence, IMN includes IIN and does also consider interactions among ions and particles, like recombination and attachment.

Yu (2006) developed a detailed model to simulate the IMN process. Results from this model point towards the dominant role of ions in NPF, especially, when the actual aerosol charged fraction is elevated in comparison to the equilibrium charging state (Yu and Turco, 2011). On the other hand, when comparing formation rates of charged particles to total particle formation rates, only a small fraction (usually less than $10 \%$ ) of the particle formation can be attributed to IIN (Manninen et al., 2009a, 2010). However, this approach does not account for ion-ion and ion-particle interactions, which are potentially contributing largely to NPF (Yu and Turco, 2011). Only recently, Kulmala et al. (2013) and Kontkanen et al. (2013) published results of field measurements with a sophisticated set of instruments, covering the size range where the very first steps of NPF take place. From their data and theoretical calculations of ion-ion recombination, Kulmala et al. (2013) and Kontkanen et al. (2013) concluded that pure neutral nucleation processes dominate over IMN.

Atmospheric ions are generally classified according to their electric mobility diameter $D_{\mathrm{m}}$ into three classes: (1) small ions or cluster ions $\left(D_{\mathrm{m}}<1.6 \mathrm{~nm}\right)$, (2) intermediate ions $\left(1.6 \mathrm{~nm}<D_{\mathrm{m}}<7.4 \mathrm{~nm}\right)$ and (3) large ions $\left(D_{\mathrm{m}}>\right.$ $7.4 \mathrm{~nm}$ ) (e.g., Hirsikko et al., 2011). Small atmospheric ions are always present in the atmosphere, being mainly generated by radioactive decay and cosmic radiation. The total concentration of small ions varies spatially and temporally, depending on ion sources and sinks (Hirsikko et al. (2011) and references therein). Elevated concentrations of intermediate and large ions are usually only present during (1) NPF events, where small ions grow due to condensation of precursor gases, (2) snow fall associated with high wind speeds, where friction processes between the snowflakes are thought to be a source for intermediate ions (Virkkula et al., 2007), and (3) rain, where the splashing of rain droplets generates intermediate ions due to the balloelectric effect (Tammet et al., 2009).

Only during the last decade, appropriate instrumentation became available to measure neutral and charged cluster size distributions down to diameters relevant for NPF (Kulmala et al., 2012). One instrument capable of measuring ions down to $D_{\mathrm{m}}$ of about $0.8 \mathrm{~nm}$ and neutral particles down to $2 \mathrm{~nm}$ is the neutral cluster and air ion spectrometer (NAIS) (Manninen et al., 2009b; 2011; Mirme and Mirme, 2013). In this paper, we present measurements performed with the NAIS during NPF. A new approach to evaluate the data is proposed to elucidate the interactions of ions and neutral particles in the formation and growth of atmospheric particles.

\section{Measurements and data analysis}

\subsection{Measurement setup}

New particle formation (NPF) events were observed from 17 June to 18 August 2012 at the Waldstein ecosystem research site in the Fichtelgebirge mountain range, NE Bavaria, Southern Germany. The measurements were carried out in a coniferous forest $\left(50^{\circ} 08^{\prime} 35^{\prime \prime} \mathrm{N}, 11^{\circ} 51^{\prime} 49^{\prime \prime} \mathrm{E} ; 776 \mathrm{~m}\right.$ a.s.1.) dominated by Norway spruce. NPF was measured by means of a neutral cluster and air ion spectrometer (S/N NAIS15) (Airel Ltd., Tartu, Estonia) and a mobility particle size spectrometer (reference system of TROPOS, Leipzig, Germany; Wiedensohler et al., 2012).

The NAIS is capable of measuring neutral particles in the diameter range from about $2 \mathrm{~nm}$ to $42 \mathrm{~nm}$ and atmospheric ions in the range of $0.8 \mathrm{~nm}$ to $42 \mathrm{~nm}$ (Manninen et al., 2011). The NAIS is composed of two cylindrical differential mobility analyzers (DMA), each with a sample flow of 30 standard liters per minute (SLM) and a sheath flow of 60 SLM. Each DMA is equipped with 21 electrometers for simultaneous detection of ions. Positive and negative ions are analyzed separately in a positive and a negative DMA, respectively. The NAIS can be used in different operating modes. In the particle mode, clusters are charged by corona discharge prior to the mobility analysis in one of the DMAs. During ion measurement mode the sample is directed to the DMAs without any prior treatment. The offset mode is used for detection of the electrometer background noise level. To do this, charging to opposite polarity and an electric filter is activated inhibiting the introduction of ions to the DMAs. During the whole campaign the NAIS was operated alternatingly with these three modes: offset mode, ion mode and particle mode. The cycle time of the consecutive modes was $200 \mathrm{~s}$, with the particle mode set to $66 \mathrm{~s}$, the ion mode set to $67 \mathrm{~s}$ and the offset mode set to $67 \mathrm{~s}$. Therefore, the overall temporal resolution of the NAIS was $200 \mathrm{~s}$.

In particle mode, the recorded number size distribution is inverted by the instrument software, assuming the Fuchscharge equilibrium of the sample prior to charging and that all classified particles are singly charged. However, if the particle population is not in charge equilibrium but either overcharged or undercharged, the NAIS will overestimate or underestimate the total particle concentrations, respectively (Kulmala et al., 2012). During NPF the charging state of aerosol particles was observed to be frequently overcharged (Gagné et al., 2010; Iida et al., 2006; Laakso et al., 2007). Additionally, an overestimation of the total particle concentration by a factor of $2-3$ is a general characteristic of NAIS 


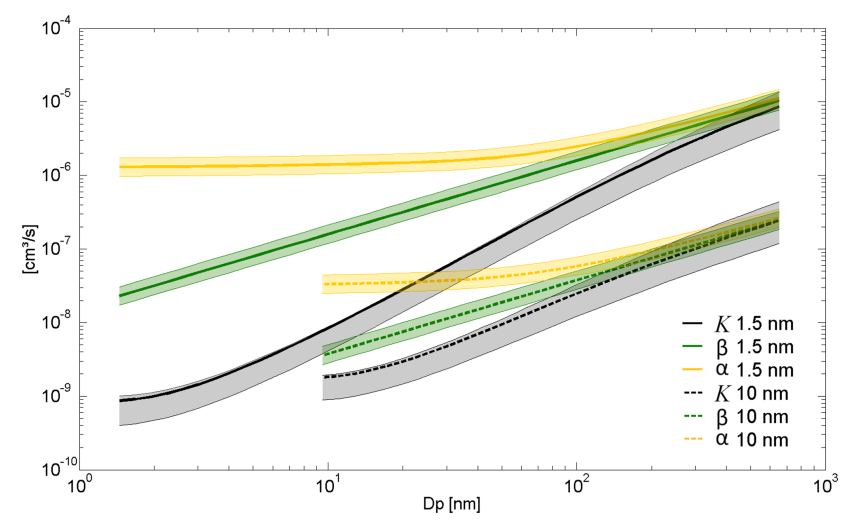

Figure 1. Coagulation coefficient $\mathrm{K}$, attachment coefficient $\beta$ and recombination coefficient $\alpha\left[\mathrm{cm}^{3} \mathrm{~s}^{-1}\right]$ for small cluster ions and particles $(1.5 \mathrm{~nm}$, solid lines) and large ions and particles $(10 \mathrm{~nm}$, dashed lines) as a function of ion/particle diameter $D_{\mathrm{p}}$. Shaded areas denote the variability of the respective coefficients, please refer to the Appendix for details.

instruments, as was shown by an intercomparison of several NAIS instruments by Gagné et al. (2011). Therefore, total particle concentrations in this study are very likely to be overestimated. In the ion mode, no charging of the sample is performed and the DMAs sample the naturally charged clusters. The NAIS is described in more detail by Manninen et al. (2009b) and Mirme and Mirme (2013).

The particle number size distributions measured with the mobility particle size spectrometer cover a diameter size range from $10 \mathrm{~nm}$ to $680 \mathrm{~nm}$ with a temporal resolution of 5 min. It was operated with a closed loop sheath flow of 5 SLM and a sample flow of 1 SLM. More details about the mobility particle size spectrometer are described in Wiedensohler et al. (2012; cf. Fig. 1). Both instruments were located in a container on a clearing in the forest with the inlets pointing towards east, at a height of $2 \mathrm{~m}$ above ground. Additionally, meteorological parameters including ozone concentration, wind speed, wind direction, temperature, relative humidity as well direct and diffuse solar radiation were measured at the forest clearing.

To obtain robust information about the processes governing NPF from measurements at a fixed location, the analyzed nucleation events have to be of regional character, and occur in a generally homogenous air mass. The homogeneity of air masses was assessed by considering the following parameters: wind direction, wind speed, ozone concentration, relative humidity and particle concentration in the diameter range from 4 to $10 \mathrm{~nm}$. Only when wind speeds varied less than $0.5 \mathrm{~m} \mathrm{~s}^{-1}$ and wind directions varied less than $60^{\circ}$ prior and during NPF, and all other parameters showed a continuous and consistent progression, the air mass was judged to be homogeneous.

The focus of this study is to determine ion interactions during NPF measured with the NAIS. Hence, the data of the mo- bility particle size spectrometer was mainly considered for calculations of ion and total particle sink rates. For this purpose, the NAIS particle data were merged with this data by means of a linearly weighted merging algorithm in the overlapping region of both instruments between 15 and $27 \mathrm{~nm}$. The mobility particle size spectrometer was measuring with a 5 min temporal resolution and its size bins were different from the NAIS size bins. Both the size bins and the time resolution were interpolated to match the NAIS time resolution and size bins. The resultant particle number size distribution between $2 \mathrm{~nm}$ and $680 \mathrm{~nm}$ was used for calculating the sink rates for ions and total particles according to Hõrak et al. (2008); Kulmala et al. (2012) and Tammet and Kulmala (2005).

\subsection{Interactions of ions and neutral particles}

The major interactions of ions and neutral particles among themselves and with the background aerosol particle population are (1) coagulation of neutral particles, (2) attachment of ions to neutral particles and (3) recombination of ions with ions of opposing polarity. The magnitude of these interactions can be calculated theoretically as corresponding coefficients (see appendix for the formulations).

Coagulation (1) is an important sink for freshly nucleated particles and a factor enhancing the particle growth rate (GR) during NPF events (Kulmala et al., 2004b). To determine the size-dependent coagulation coefficient $K_{i j}$, an approximation from Tammet and Kulmala (2005) was used (cf. Eqs. A1 and A2). The theoretical approach for $K_{i j}$ is valid for the interaction of neutral particles and clusters of all diameters $i$ and $j$.

The ion aerosol attachment (2) is described by the attachment coefficient $\beta$ for the interaction of small air ions with neutral particles. $\beta$ is commonly assumed constant $\left(1 \times 10^{-8} \mathrm{~cm}^{3} \mathrm{~s}^{-1}\right)$ when determining ion formation rates, where the attachment of small ions to neutral particles of a large diameter is considered a source for ions of the same diameter (Hirsikko et al., 2011; Kulmala et al., 2012; Manninen et al., 2010). However, this size-independent approach is only an approximation. In particular, when the diameter $i$ of neutral particles is greater than $10 \mathrm{~nm}$, a constant value is inaccurate (cf. green solid line in Fig. 1). Therefore, when calculating ion sinks, the size dependence of $\beta$ has to be taken into account. The size dependent $\beta_{i j}$ varies by three orders of magnitude, when the interactions of small ions of size $j$ with neutral particles of size $i$ are considered (cf. solid green line in Fig. 1; Hoppel and Frick, 1990; Hõrrak et al., 2008; Tammet and Kulmala, 2005). For this study, we determined $\beta_{i j}$ by applying a formulation by Hõrrak et al. (2008), which is an approximation of the tabulated results by Hoppel and Frick (1990) (cf. Eqs. A3 and A4). Since intermediate and large ions also have a slightly enhanced attachment probability compared to pure neutral coagulation (cf. Fig. 1, dashed 
lines), we extrapolated $\beta_{i j}$ for all measured ion size ranges, still using the formulation by Hõrrak et al. (2008).

In principle, the ion-ion recombination (3) can also be described by the attachment coefficient, assuming the interaction of clusters with opposite charges. Usually, the recombination coefficient is denoted as $\alpha$ and assumed to be constant $\left(1.6 \times 10^{-6} \mathrm{~cm}^{3} \mathrm{~s}^{-1}\right)$ when the interaction among small ions is considered (Hoppel and Frick, 1990; Kulmala et al., 2013; Tammet and Kulmala, 2005). Considering the case of cluster ions of diameter $j$ interacting with oppositely charged clusters of a similar diameter $k, \beta_{j k}$ should be comparable to the constant value of $\alpha$ (Hoppel and Frick, 1986). In fact, $\beta_{j k}$ for ions with $j=1.5 \mathrm{~nm}$ interacting with oppositely charged ions with $k=1.5 \mathrm{~nm}$, as used in this study, is $1.3 \times 10^{-6} \mathrm{~cm}^{3} \mathrm{~s}^{-1}$ (solid orange line in Fig. 1). Therefore, $\beta_{j k}$ for the interaction of oppositely charged clusters in the sizes class $j$ and $k$, i.e., the size-dependent recombination coefficient, will be denoted as $\alpha_{j k}$ in the following (Eq. A5).

The theory for ion attachment and recombination was developed to calculate the attachment of small ions to larger particles or ions, in order to theoretically assess the particle charge distribution in a bipolar ion environment (Hoppel and Frick, 1986, 1990; Reischl et al., 1996). The interaction of intermediate and large ions with even larger neutral or charged particles was not the aim of these studies. Nevertheless, the sinks and sources for all ion sizes have to be taken into account when analyzing ion interactions in NPF. Therefore, we chose to use the approximated theory from Hõrrak et al. (2008) to obtain a first order approximation of the coefficients governing the behavior of larger ions, and to apply the calculations also for larger diameters. A validation of this approach is given by comparing the size dependence of $\beta$ and $\alpha$ to $K$. In Fig. 1, all three coefficients are depicted for aerosols of two different diameters $(1.5$ and $10 \mathrm{~nm})$. As electrical effects will enhance the probability of an encounter of two particles, $K$ is the lower limit for the three considered interactions. When small ions $(1.5 \mathrm{~nm})$ and small neutral particles interact with each other (green solid line in Fig. 1), the electrical effect can enhance the collision probability by more than one order of magnitude. Considering the interaction of oppositely charged ions, the enhancement can be greater than three orders of magnitude (orange solid line in Fig. 1). The largest differences are found for interactions of small particles or ions. However, when small ions interact with larger particles or ions, $\alpha$ and $\beta$ approach $K$, indicating a smaller influence of the charge on the collision probability. A similar pattern can be seen when considering the interaction of large ions with larger aerosol particles (dashed lines in Fig. 1). For the interaction of particles or ions with a diameter of $10 \mathrm{~nm}$, $\alpha$ and $\beta$ decrease about $1-2$ orders of magnitude while $K$ is not that strongly affected. The difference among the three coefficients is less pronounced, pointing towards a smaller influence of the charge on collision probabilities when larger ions and particles are considered.

\subsection{Ion-ion recombination}

Knowing the recombination coefficient $\alpha_{j k}$ and the number concentration of ions of both polarities, a theoretical number size distribution of neutral particles from ion-ion recombination can be deduced. Kontkanen et al. (2013) and Kulmala et al. (2013) proposed a method to calculate the number size distribution resulting from recombination. Both authors used a constant value of $1.6 \times 10^{-6} \mathrm{~cm}^{3} \mathrm{~s}^{-1}$ for $\alpha$. This is justified since only the recombination of charged clusters below $2.1 \mathrm{~nm}$ in diameter was considered. However, we use the size-dependent $\alpha_{j k}$ for our approach as the recombination of charged clusters up to $42 \mathrm{~nm}$ is considered. Furthermore, Kulmala et al. (2013) used a very simple balance equation, by assuming recombination as the only source of neutral clusters and coagulations as the only sink. Similar to Kontkanen et al. (2013), our analysis includes additional sinks and source terms. The sources are given by the recombination of positive and negative ions contributing to size class $i$ as well as the growth of recombined neutral particles into size class $i$. The sinks include (1) the coagulation sink $\left(\operatorname{CoagS}_{i}\right.$; cf. Eq. A6) describing the loss of the recombined neutral particles to the background neutral particles, (2) the charging sink $\left(\mathrm{CharS}_{i}^{ \pm}\right.$; cf. Eq. A7) defining the number of recombined neutral particles in size $i$ being charged either positively or negatively by the present ions (Hõrak et al., 2008), and (3) the growth sink, describing the growth of recombined neutral particles out of the size class $i$. The balance equation for recombination is therefore:

$$
\begin{aligned}
& \frac{\mathrm{d} N_{i}^{\mathrm{rec}}}{\mathrm{d} t}=\sum_{j k} r_{j k} \alpha_{j k} N_{j}^{+} N_{k}^{-}+N_{i-1}^{\mathrm{rec}} \frac{\mathrm{GR}_{i-1}}{\Delta D p}-N_{i}^{\mathrm{rec}} \\
& \left(\mathrm{CoagS}_{i}+\mathrm{CharS}_{i}^{+}+\mathrm{CharS}_{i}^{-}+\frac{\mathrm{GR}_{i}}{\Delta D p}\right)
\end{aligned}
$$

where, $N_{i}^{\text {rec }}$ is the number concentration of recombined neutral particles in size class $i$ and $r_{j k}$ is a coefficient allocating the recombined neutral particles to size class $i \cdot \frac{\mathrm{GR}_{i}}{\Delta D p}$ is the neutral growth rate normalized by the size bin width and $N_{j}^{+}$ and $N_{k}^{-}$are the positive and negative ion number concentrations, respectively. Assuming steady state conditions, Eq. 1 provides the number of recombined neutral particles for each size class $i$. Breakup of the formed clusters as proposed by Kontkanen et al. (2013) and Kulmala et al. (2013) is not taken into account in our formulation. Since the concentration of recombination products did never reach the measured neutral cluster concentration, making the determination of a breakup term impossible.

The key parameter governing the concentration of small ions in the atmosphere is the ionization rate $Q$. For our site, $Q$ was calculated by means of a simplified ion equilibrium equation, assuming steady-state equilibrium (Hoppel and Frick, 1986). This equation assumes the ion production rate to be a function of two ion sink terms, the recombination 


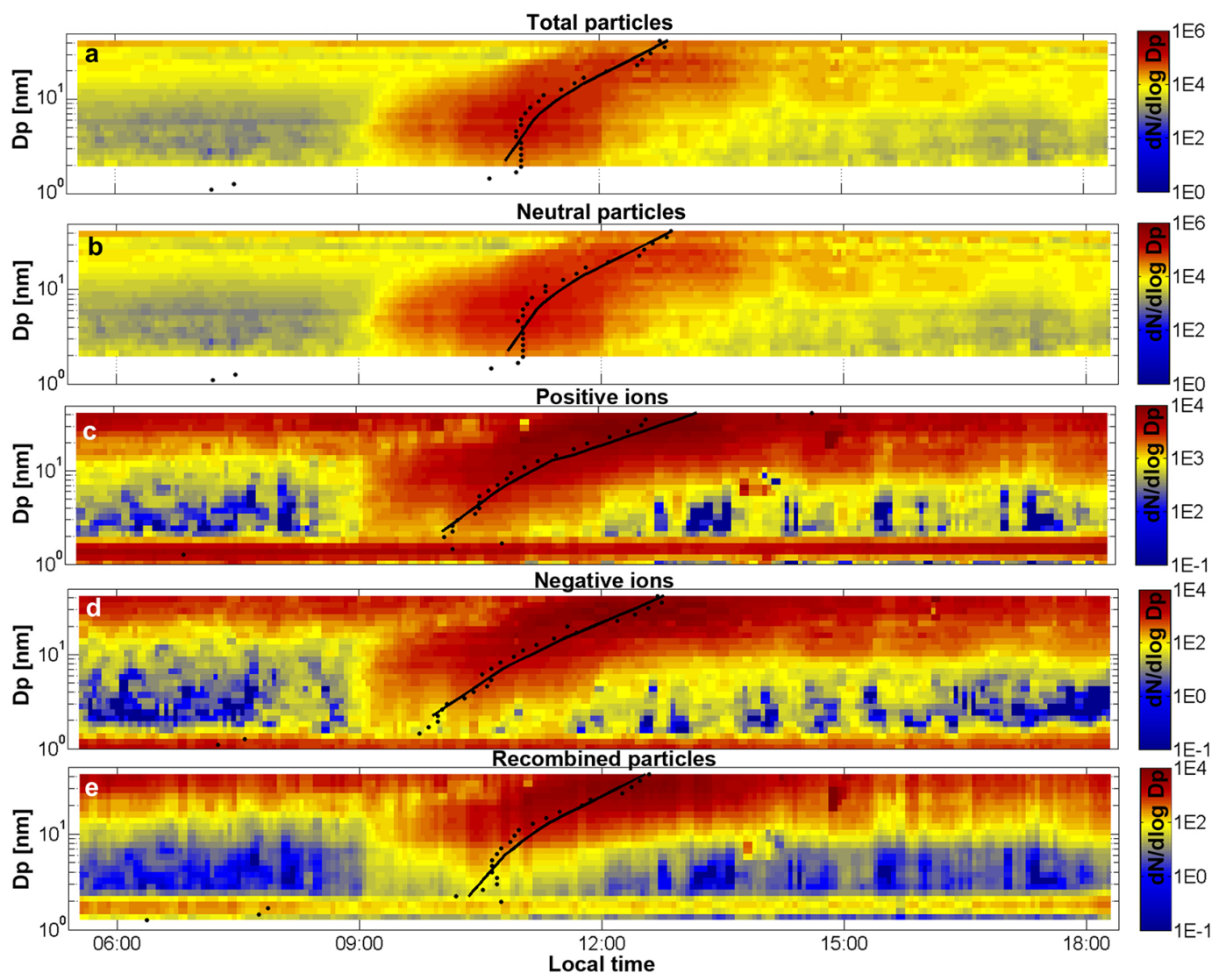

Figure 2. NPF event of 12 August 2012 as measured with the NAIS. Shown are (a) total particles, (b) neutral particles, (c) positive ions, (d) negative ions and (e) calculated neutral particles from ion-ion recombination. Black-filled circles denote the concentration maxima for each size class, while black lines are smoothed fits in order to obtain continuous growth rates.

and the attachment of ions to the present background aerosol (cf. Eq. A8).

\subsection{Formation- and growth rate}

The formation rate $J$ describes the flux of particles or ions into a defined size interval. $J$ was calculated for every size class using Eqs. 9 and 10 from Kulmala et al. (2012).

The growth rates were also deduced for every size class, this was done separately for total particles $\left(\mathrm{GR}_{\mathrm{t}}\right)$ as well as positive $\left(\mathrm{GR}_{\mathrm{pos}}\right)$ and negative ions $\left(\mathrm{GR}_{\mathrm{neg}}\right)$. Growth rates were determined using the maximum concentration method described in detail in Sect. 6a by Kulmala et al. (2012). In order to determine the point in time of the maximum concentration (black-filled circles in Fig. 2), we applied a least square polynomial smoothing filter (Savitzky and Golay, 1964) to each of the NAIS size classes. Further smoothing of the determined times of maximum concentration resulted in smooth size dependent growth rates (black curves in Fig. 2). The determination of GRs from particle/ion measurements in the troposphere are always associated with uncertainties (Yli-Juuti et al., 2011) as the growth of a particle population is a dynamic process with several influenc- ing factors. Therefore, the result of a GR analysis from field measurements will always only result in an approximation of the true GR. Besides, as the probability of particles carrying multiple charges in the NAIS increases with particle diameter, the measured number size distribution for larger sizes is less reliable. However, the growth rates for particles smaller than $20 \mathrm{~nm}$ in diameter give reasonable results. For ion/particle diameters above $20 \mathrm{~nm}$, the applied method results in an overestimation of the growth rates (cf. Fig. 2). By comparing concentrations as well as growth rates of total particles (Fig. 2a) and neutral particles (Fig. 2b), it becomes evident that neutral and total particles exhibit equivalent values. Therefore, data from the NAIS's total particle measurements are used to describe neutral particle characteristics in the following. As the same procedure was applied to all ion and particle measurements, the determined growth rates are well comparable. Further, a correction for self-coagulation of the growing mode was applied to obtain the rates for pure condensational growth (Leppä et al., 2011). 
Table 1. Median, 25th and 75th percentile of cluster ion concentrations $\left[\mathrm{cm}^{-3}\right]$ (diameter $<1.6 \mathrm{~nm}$ ) during 8 selected NPF event and 13 non-event days, measured with the NAIS during summer 2012 at the Waldstein site.

\begin{tabular}{llll}
\hline & Median & 25th & 75th \\
\hline Non-event negative & 129 & 101 & 186 \\
NPF-event negative & 148 & 126 & 176 \\
Non-event positive & 314 & 252 & 422 \\
NPF-event positive & 339 & 285 & 395 \\
\hline
\end{tabular}

\section{Results}

\subsection{General event characteristics}

Simultaneous measurements of neutral and charged clusters and particles at the Waldstein ecosystem research site from 17 June to 18 August 2012 showed a frequent occurrence of new particle formation events. Typically, the events occurred during sunny morning hours while wind directions from the east prevailed. However, several events did also occur in the afternoons and when wind directions were not from the east. A total number of $17 \mathrm{NPF}$ events ( $28 \%$ of measurement period) were observed, while 29 days $(47 \%)$ could not be defined as clear events but did still show particle formation. Non-event days were less frequent with only 15 out of 61 days. Since the measurements were taken at a fixed location, a reliable evaluation of the patterns governing the formation and growth of particles were only possible in homogeneous air masses. After careful evaluation for homogeneous air masses as described above, a total of 8 events were chosen for detailed analysis. Figure 2 shows a typical NPF event. Growth rates of those 8 days compare well to prior observations, reporting growth rates in the range from 2.2 to $5.7 \mathrm{~nm}$ $\mathrm{h}^{-1}$ at the same location (Held et al., 2004). For particles in diameter range $2-3 \mathrm{~nm}$ median total particle growth rates $\left(\mathrm{GR}_{\mathrm{t}}\right)$, negative $\left(\mathrm{GR}_{\text {neg }}\right)$ and positive growth rates $\left(\mathrm{GR}_{\mathrm{pos}}\right)$ were found to be $4.1 \mathrm{~nm} \mathrm{~h}^{-1}, 2.4 \mathrm{~nm} \mathrm{~h}^{-1}$ and $2.8 \mathrm{~nm} \mathrm{~h}^{-1}$, respectively. Median formation rates $J$ for $2-3 \mathrm{~nm}$ particles were in the order of $3.5 \mathrm{~cm}^{-3} \mathrm{~s}^{-1}, 0.015 \mathrm{~cm}^{-3} \mathrm{~s}^{-1}$ and $0.02 \mathrm{~cm}^{-3} \mathrm{~s}^{-1}$ for total, negative and positive particles, respectively.

\subsection{Ion concentrations and ionization rates at Waldstein}

The Waldstein site is located in the Fichtelgebirge mountain range, NE Bavaria. The Fichtelgebirge is known for its enhanced background radioactive radiation levels. In particular, radon is elevated, reaching soil gas activity concentrations of up to $4000 \mathrm{kBq} \mathrm{m}^{-3}$ (Kemski et al., 2001; Lüers et al., 2007). As the primary sources for atmospheric ions are radon decay, gamma radiation and cosmic radiation (Hirsikko et al., 2011), ion concentrations and ionization rates $Q$ are expected to be elevated at the Waldstein site. The mea- surements with the NAIS in summer 2012 showed median concentrations of positive and negative cluster ions on NPF event days of 339 and $148 \mathrm{~cm}^{-3}$, respectively (cf. Table 1). The cluster ion concentrations show a clear diurnal variation both on NPF event days and non-event days (Fig. 3). Lüers et al. (2007) conducted radon measurements at the Waldstein site and found similar diurnal patterns, hinting towards radon as the major ionization source. Furthermore, our measurements show that cluster ion concentrations are slightly enhanced on NPF events days (Table 1). Nevertheless, the concentrations seem quite low compared to values measured at various locations around the world. Ion concentrations measured at 2 meter above ground are typically in the range of 500 to $1000 \mathrm{~cm}^{-3}$ (Hirsikko et al., 2011). In summer 2013, measurements with an air ion spectrometer (AIS) were performed at the same clearing at the Waldstein site. The AIS is very similar to the NAIS, except that it is not equipped with a corona charger for charging the neutral particles. Measurements with the AIS resulted in typical positive and negative cluster ion concentrations of 600 and $900 \mathrm{~cm}^{-3}$, respectively. These values compare much better with the concentrations published by Hirsikko et al. (2011), and range close to the upper end of typical values. The obvious discrepancy between the AIS and NAIS may be explained by different inlets of the two instruments. The inlet of the NAIS was $1.8 \mathrm{~m}$ long and was bent by $180^{\circ}$, while the AIS inlet was about $1 \mathrm{~m}$ long and had a bending of only $90^{\circ}$. An enhanced ion loss in the NAIS inlet due to diffusion is probable, as the penetration for cluster ions through the NAIS inlet is only about half of the penetration through the AIS inlet. Further, electrostatic losses for the NAIS measurements could give an explanation for the generally lower concentrations of negative ions in compare to positive ions. Negative ions have a higher electrical mobility and are therefore preferentially lost due to a present electrostatic field. Considering the much higher ion concentrations and the optimized inlet of the AIS, absolute ion concentrations measured with the NAIS in 2012 are probably underestimated. However, the underestimation of the absolute concentration does not affect the determination of the growth rates with the maximum concentration method.

The median ionization rates $Q$ determined with the NAIS during NPF events are 0.8 and $0.9 \mathrm{~cm}^{-3} \mathrm{~s}^{-1}$ for negative and positive cluster ions, respectively (cf, Table 2 ). The calculated $Q$ s are most probably underestimated since $Q$ depends directly on ion concentrations, which are underestimated by the NAIS. Furthermore, the simplified balance equation for determining $Q$ does not consider all active ion sinks, resulting in a general underestimation of about a factor of 2 (Hõrrak et al., 2008). Considering these facts, $Q$ was probably well above 3 ion pairs $\mathrm{cm}^{-3} \mathrm{~s}^{-1}$ during summer 2012 at Waldstein. 


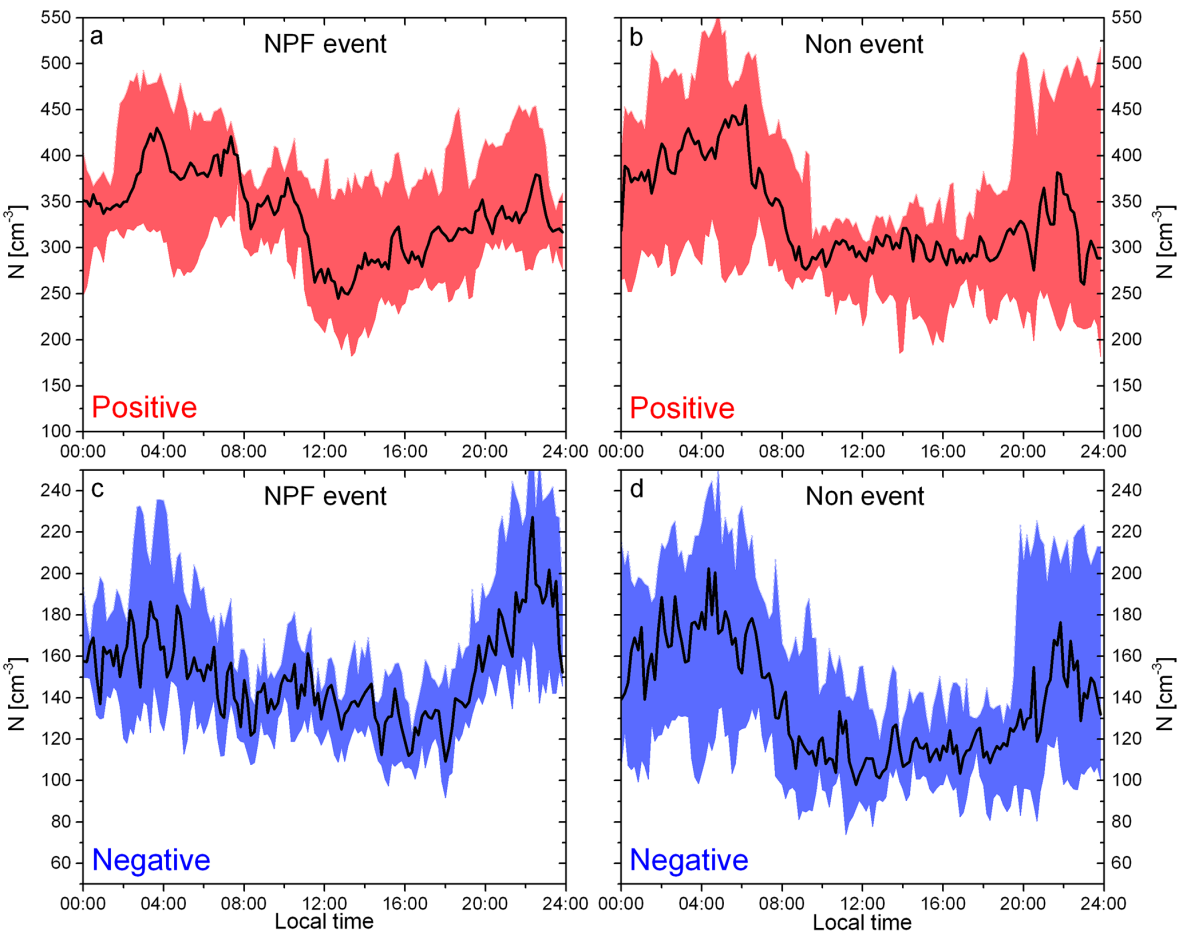

Figure 3. Median diurnal variation of cluster ion concentrations (diameter $<1.6 \mathrm{~nm}$ ) during 8 selected NPF event days (a, c) and 13 non-event days (b, d), as measured with the NAIS during summer 2012 at the Waldstein site. The shaded areas denote the 25th and 75th percentile.

Table 2. Event features of all 8 selected NPF events used for this study. Shown are the following: NPF event start time (CET), prevailing wind direction, time difference $\Delta t$ of $2-3 \mathrm{~nm}$ ions [min.], growth rates GR of 2-3 nm total particles and ions [nm $\mathrm{h}^{-1}$ ], formation rates $J$ of 2-3 nm total particles and ions $\left[\mathrm{cm}^{-3} \mathrm{~s}^{-1}\right]$ and ionization rates $Q$ for cluster ions $\left[\mathrm{cm}^{-3} \mathrm{~s}^{-1}\right]$. Values for $Q_{\text {neg }}, Q_{\text {pos }}, J_{\text {neg }}$ and $J_{\text {pos }}$ are probably underestimated, please refer to Sect. 3.2 for detail.

\begin{tabular}{lllllllllllll}
\hline Date & Start & $\begin{array}{l}\text { Wind } \\
\text { sector }\end{array}$ & $\Delta t_{\text {neg }}$ & $\Delta t_{\text {pos }}$ & $\mathrm{GR}_{\mathrm{t}}$ & $\mathrm{GR}_{\text {neg }}$ & $\mathrm{GR}_{\text {pos }}$ & $J_{\mathrm{t}}$ & $J_{\text {neg }}$ & $J_{\text {pos }}$ & $Q_{\text {neg }}$ & $Q_{\text {pos }}$ \\
\hline 17 June 2012 & 13:00 LT & $\mathrm{W}$ & 20 & 5 & 2.8 & 6.3 & 3.2 & 0.4 & 0.02 & 0.02 & 0.4 & 0.4 \\
19 June 2012 & 12:00 LT & $\mathrm{E}$ & -62 & 0 & 1.5 & 2 & 1.9 & 0.4 & 0.002 & 0.006 & 0.5 & 0.7 \\
4 July 2012 & $09: 30 \mathrm{LT}$ & $\mathrm{E}$ & 33 & 22 & 2.9 & 2.4 & 2.3 & 0.5 & 0.006 & 0.007 & 0.7 & 0.9 \\
23 July 2012 & $07: 30 \mathrm{LT}$ & $\mathrm{E}$ & 102 & 97 & 5.3 & 1.5 & 1.4 & 5 & 0.02 & 0.02 & 0.9 & 1 \\
24 July 2012 & $08: 30 \mathrm{LT}$ & $\mathrm{E}$ & 67 & 42 & 9 & 2.4 & 3.7 & 2.3 & 0.004 & 0.01 & 0.8 & 0.9 \\
12 August 2012 & $08: 30 \mathrm{LT}$ & $\mathrm{E}$ & 53 & 38 & 6.9 & 3.2 & 3.8 & 4.7 & 0.02 & 0.04 & 1.1 & 1.2 \\
13 August 2012 & $07: 30 \mathrm{LT}$ & $\mathrm{E}$ & 17 & 13 & 6 & 3.5 & 4.4 & 5.2 & 0.02 & 0.05 & 1.3 & 1.6 \\
17 August 2012 & $08: 30 \mathrm{LT}$ & $\mathrm{E}$ & 10 & 5 & 1.6 & 1.6 & 1.8 & 5.2 & 0.01 & 0.02 & 0.8 & 0.8 \\
\hline Median & - & - & 26.5 & 17.5 & 4.1 & 2.4 & 2.75 & 3.5 & 0.015 & 0.02 & 0.8 & 0.9 \\
\hline
\end{tabular}

\subsection{Time difference}

In all 8 evaluated NPF events, 2 nm ions (NAIS size bin limits were $1.8-2.1 \mathrm{~nm}$ ) showed a concentration increase before the concentrations of total particles of the same size increased. Figure 4a shows the course of concentration for $2 \mathrm{~nm}$ total particles and ions for an exemplary NPF event on $12 \mathrm{Au}$ gust 2012. The occurrence of an earlier ion formation prior to total particle formation seems to be a typical pattern during NPF. Manninen et al. (2010) report of NAIS measure- ments during NPF at several locations in Europe. They also observed the earlier formation of $2 \mathrm{~nm}$ ions prior to $2 \mathrm{~nm}$ total particle formation in different environments. However, this behavior was not investigated in more detail in other studies. When considering the concentrations of larger particles and ions, the time gap between the appearance of charged and total particles becomes smaller with increasing particle size (Fig. 4b-e). This behavior was observed throughout all NPF events considered in our study. In order to determine the time difference $\Delta t$ between the appearance of ions and total 


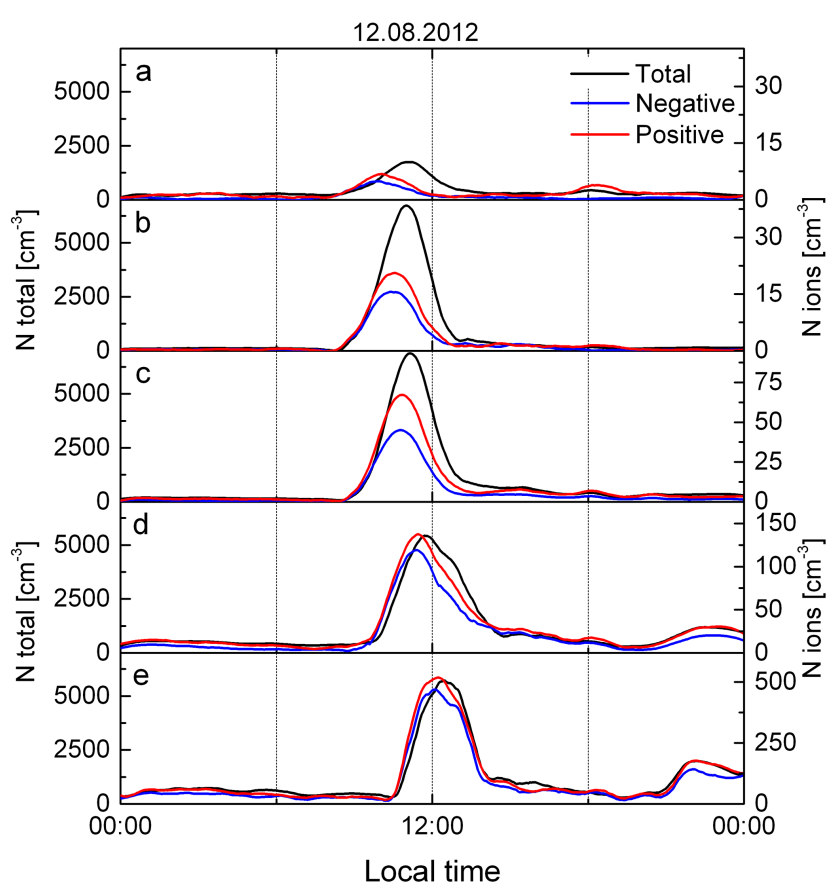

Figure 4. Temporal evolution of total particle concentrations as well as positive and negative ion concentrations in diameter ranges of (a) $1.8-2.1 \mathrm{~nm}$, (b) $3.7-4.3 \mathrm{~nm}$, (c) $7.6-8.8 \mathrm{~nm}$, (d) $13.6-15.7 \mathrm{~nm}$ and (e) $21.1-24.5 \mathrm{~nm}$. The data originates from single NAIS size channels, measured during the NPF event on 12 August 2012 at Waldstein. Ion concentrations increase during the growth process, while total particle concentrations increase rapidly at the beginning of NPF but begin to decrease at diameters above $8 \mathrm{~nm}$. Note that the ion concentrations (right axes) are always smaller than the particle concentrations (left axes). Data was smoothed for illustrational purpose.

particles, a cross-correlation analysis was performed individually for each size class. Cross-correlation analysis is a standard procedure to analyze time shifts in two time series. The result of the cross-correlation analysis can be seen in Fig. 5. For small particles, $\Delta t$ is largest and sharply decreases as the particle diameter increases, eventually reaching $\Delta t=0$ for diameters of about $20 \mathrm{~nm}$. Therefore, the total particles seem to grow faster than ions after the onset of a NPF event, as $\Delta t$ becomes smaller during the growth process.

\subsection{Growth rates}

Due to the decrease of $\Delta t$ during NPF, $\mathrm{GR}_{\mathrm{t}}$ is expected to differ from $\mathrm{GR}_{\text {neg }}$ and $\mathrm{GR}_{\text {pos }}$, especially when considering small particle diameters. In fact, our analysis yields an increased $\mathrm{GR}_{\mathrm{t}}$ compared to $\mathrm{GR}_{\text {neg }}$ and $\mathrm{GR}_{\text {pos }}$. At this point, it should be mentioned once more that the growth rates above an ion/particle diameter of $20 \mathrm{~nm}$ are most probably overestimated by the maximum concentration method. Figure $6 \mathrm{a}$ shows the growth rates for the NPF event on 4 July 2012. $\mathrm{GR}_{\text {neg }}$ and $\mathrm{GR}_{\text {pos }}$ are similar to each other, while the total particles grow faster. Fig. 6b shows the median growth rates of all 8 regional NPF events. An enhanced $G_{t}$ is evident in the median values. The enhanced $\mathrm{GR}_{t}$ compared to charged particle growth rates deviates from theories for pure condensational growth, where the presence of a charge enhances the growth rates of small and intermediate ions (e.g., Yu and Turco, 2000; Yue and Chan, 1979). Therefore, condensational growth on its own cannot explain the apparent GR differences. To further support our observations at the Waldstein site, we analyzed additional data recorded with a NAIS instrument during summer 2008 at the "Melpitz" field site in NW Saxony, Germany. In these data, the same patterns are found: $\Delta t$ decreases during the growth process and total particles show an enhanced growth rate compared to ions. As the determination of the growth rates is always connected to some error, the enhancement of $\mathrm{GR}_{t}$ over to $\mathrm{GR}_{\text {neg }}$ and $\mathrm{GR}_{\text {pos }}$ cannot be regarded as significant, but still it is considered to be plausible.

\subsection{Recombination}

The number size distributions deduced from ion-ion recombination as described by Eq. 1 are generally comparable to the measured total particle distributions. However, the resulting absolute concentrations of particles from ion-ion recombination are one to three orders of magnitude smaller than the observed total particle distributions. Particularly, when diameters below $10 \mathrm{~nm}$ are considered, recombination cannot explain the abundance of total particles (cf. Fig. 2). This may be partly due to the performance of the NAIS. As described in Sect. 3.2 ion concentrations in our study are generally underestimated, while an overestimation of total particle concentrations is a typical property of NAIS instruments (Gagné et al., 2011). Therefore, the absolute values are not taken into consideration for our study. Nevertheless, the recombination gives valuable information regarding the growth behavior of neutral particles. A measure which can still be used for our analysis is the growth rate of the recombination products $\left(\mathrm{GR}_{\mathrm{rec}}\right)$. As mentioned above, $\mathrm{GR}_{\mathrm{t}}$ is elevated at small particle diameters compared to $\mathrm{GR}_{\text {neg }}$ and $\mathrm{GR}_{\text {pos }}$. $\mathrm{GR}_{\text {rec }}$ seems to behave similar to $\mathrm{GR}_{\mathrm{t}}$ as can be seen in Figs. 2 and 6. For most of the NPF events considered in our study, $\mathrm{GR}_{\text {rec }}$ is well above $\mathrm{GR}_{\text {neg }}$ and $\mathrm{GR}_{\text {pos }}$ (Fig. 6b) and sometimes matches $\mathrm{GR}_{\mathrm{t}}$ quite well (Fig. 6a).

\section{Discussion}

The 8 particle formation events at the Waldstein site considered in this study can be separated into two distinct stages. The formation of the first stable clusters and particles seem to happen in the ion fraction. Later, the ion formation step is followed by a very intense formation and growth of 

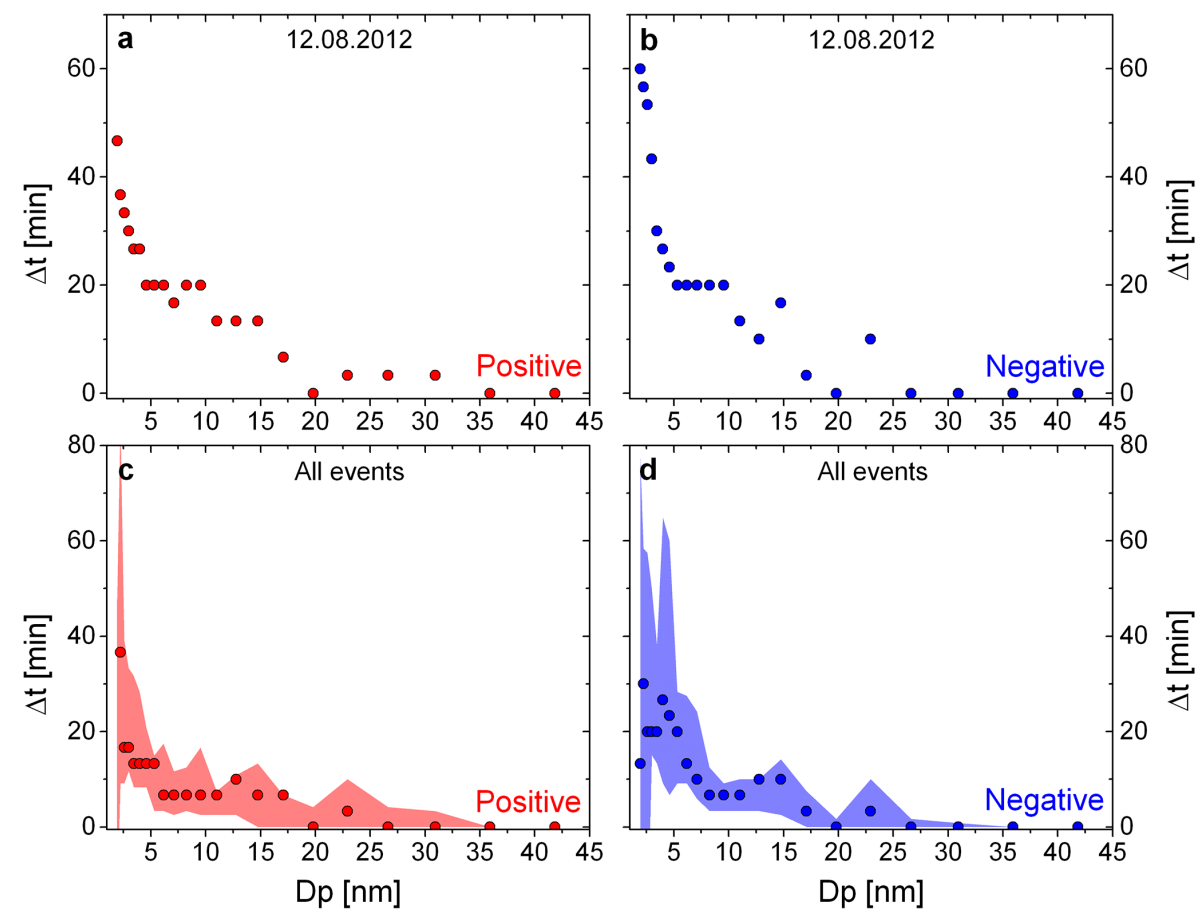

Figure 5. Results from the cross-correlation study showing the size-dependence of the time difference ( $\Delta t$ ). Appearance of (a) positive and (b) negative ions compared to total particles measured with NAIS on 12 August 2012, and median values of $\Delta t$ for all 8 selected NPF event days for (c) positive and (d) negative ions. Shaded area denote the 25 th and 75 th percentile.

neutral clusters and particles. The initial ion-induced nucleation (IIN) typically happens about $20-30 \mathrm{~min}$ before the first appearance of neutral particles (Fig. 5c, d; Table 2) at Waldstein. This observation can most likely be explained by the higher stability of charged clusters over neutral ones at a certain precursor gas saturation ratio (Enghoff and Svensmark, 2008; Yue and Chan, 1979). Furthermore, charged clusters clearly activate more easily and grow more quickly (e.g., Lushnikov and Kulmala, 2004; Winkler et al., 2008; Yu and Turco, 2000). Keeping this in mind and assuming no ionion and ion-particle interactions, the time difference between an earlier occurring ion fraction and the total particle fraction during the growth process should increase or remain constant. However, our measurements show a contrary behavior: once formed, the neutral particles grow considerably faster than the ion fraction, and eventually, the earlier occurrence of the ions vanishes completely. A possible explanation for the slower ion GR could be the diurnal variation of gas phase precursors like sulfuric acid or oxidation products of volatile organic compounds (VOCs). In the early morning hours, when the first intermediate ions are formed, the precursor gas concentrations are expected to be low. On sunny days, as were most of the considered event days, the precursor gas concentration will increase during the day. This is due to increasing VOC emissions from the forest with rising air temperature, as well as due to photochemical processes leading to the formation of sulfuric acid and oxidation of
VOCs. Therefore, the neutral particle growth which occurs later could be enhanced due to higher concentrations of precursor gases.

Additionally, ion-ion and ion-particle interactions enhance neutral particle GRs. As the potential precursor gases were not measured in this study, the focus to explain our observation will be on ion-particle interaction processes. Nevertheless, it is not expected that the observations can be explained fully by ion-particle interactions.

Considering ion-particle interactions by applying theoretical parameterizations of the attachment and recombination processes to the combined NAIS and mobility particle size spectrometer measurements, we obtained the ion-mediated or -recombined fraction of neutral particles. NAIS number concentration measurements are subject to uncertainties both for ions and total particles (Asmi et al., 2009; Gagné et al., 2011). However, growth rate analyses are not influenced by the uncertainties in NAIS number concentrations. Therefore, we chose $\mathrm{GR}_{\mathrm{rec}}$ deduced from the calculated recombination number size distribution as a measure for the influence of ions on neutral particle formation.

In general, our analyses show an earlier formation of charged particles compared to total particles (Fig. 5). When looking more closely at the time difference of appearance $(\Delta t)$ of ions and total particles, the 8 considered NPF events can be divided in two classes: (1) initial $\Delta t$ is larger than 

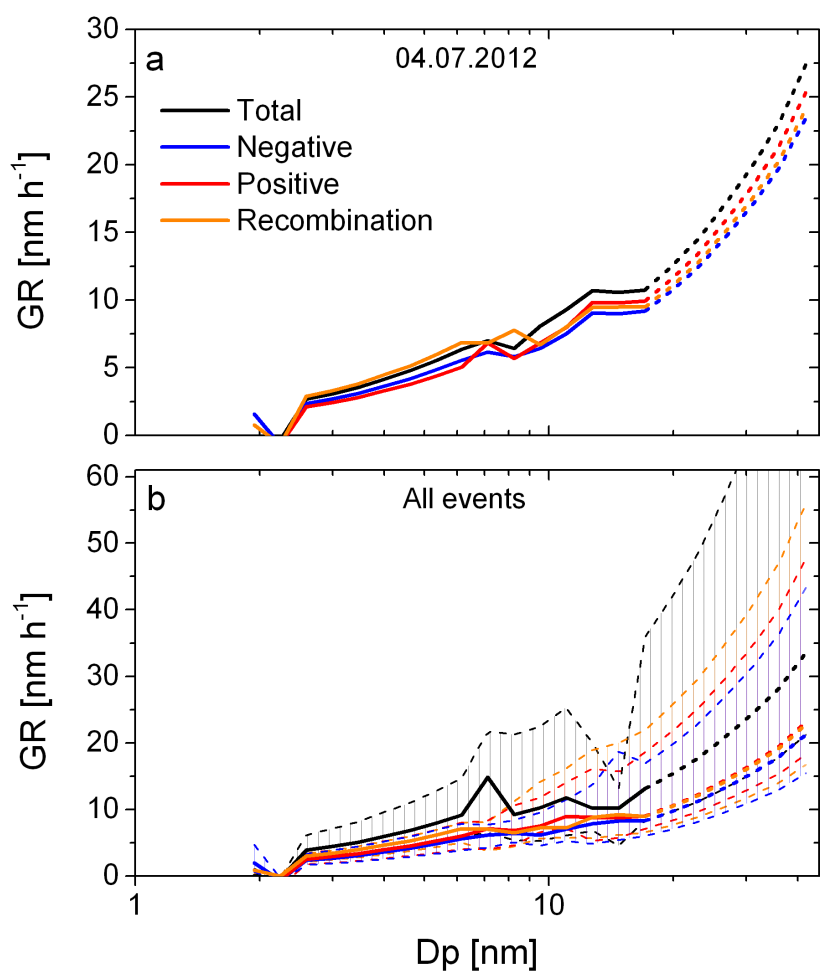

Figure 6. Growth rates of negative ions, positive ions and total particles determined from NAIS measurements, (a) for a single event on 4 July 2012 and (b) median values for all 8 selected NPF events used for this study. Hatched areas denote the 25th and 75th percentile. Additionally, $\mathrm{GR}_{\mathrm{rec}}$ deduced from ion-ion recombination is shown in orange. Dashed segments of the curves denote inaccurate growth rates.

$20 \mathrm{~min}$ (Fig. 7) and (2) initial $\Delta t$ is smaller than $20 \mathrm{~min}$ (Fig. 8).

Median values of four NPF events (4 July; 23 July; 24 July; 12 August 2012; cf. Table 2) with $\Delta t>20 \mathrm{~min}$ are shown in Fig. 7. The large differences in the growth rates for ions and total particles (Fig. 7a) are remarkable. While $\mathrm{GR}_{\text {neg }}$ and $\mathrm{GR}_{\text {pos }}$ are as expected for small diameters, $\mathrm{GR}_{\mathrm{t}}$ for small total particles is strongly elevated (cf. Table 2). This strong growth is maintained until a sharp drop for diameters above $10 \mathrm{~nm}$ is evident. The unusual sharpness of the decrease can most likely be attributed to limitations of the maximum concentration method and the inversion routine of the NAIS. Nevertheless, qualitatively the decrease in $\mathrm{GR}_{\mathrm{t}}$ is considered real, indicating a change in the prevailing growth conditions. Figure $7 \mathrm{~b}$ shows the time evolution of the growing mode's diameter of maximum concentration $\left(D p_{\max }\right)$ for both ion polarities as well as for total particles. More specifically, $D p_{\max }$ is the result of the maximum concentration method for the determination of the growth rates (cf. black lines in Fig. 2). The origin of the horizontal axis (time $=0$ ) indicates the first appearance of the total particle growing mode. The time of initial ion appearance is offset by the median of $\Delta t$ at $2 \mathrm{~nm}$ for positive and negative ions, respectively (cf. Fig. 7c, d). The initial offset of the ion growing mode is about $60 \mathrm{~min}$. As total particles exhibit a higher $\mathrm{GR}_{\mathrm{t}}$, their growing mode finally reaches the same $D p_{\max }$ as the ion modes, about 40 to $60 \mathrm{~min}$ after the first appearance of total particles.

Figure $7 \mathrm{c}$ and $\mathrm{d}$ show the time difference $(\Delta t)$ in occurrence of ions compared to total particles. $\Delta t$ exhibits a rapid decrease as the particles grow. Eventually, for particle diameters above $10 \mathrm{~nm}$, the advance of ions is fairly small and continues to decreases at a slower rate, to approach $\Delta t=0$ at about $20 \mathrm{~nm}$. Additionally, Fig. 7c and d show the independently derived time difference between the negative and positive $D p_{\max }$ to the total one (cf. Fig. 7c, d as black dotted lines). Basically, this is a comparison of $\Delta t$ derived from the cross-correlation method with the time difference derived from the maximum concentration method. The general patterns of these time differences are very similar: the rapid decrease of $\Delta t$ is clearly evident until particle diameters of about $10 \mathrm{~nm}$ are reached. For greater particle diameters the time differences of $D p_{\max }$ become negative, indicating a persistently enhanced growth rate of the total particle growing mode. However, our data do not show an advance of the total growing mode compared to the ion modes (cf. Figs. 4, 5 and $7 \mathrm{c}, \mathrm{d})$. This discrepancy may be explained by the increasing uncertainty associated with the growth rate determination for larger diameters.

Median values for four NPF events with $\Delta t<20 \mathrm{~min}$ (17 June; 19 June; 13 August; 17 August 2012; cf. Table 2) are shown in Fig. 8. The median growth rates for these events (Fig. 8a) are significantly lower compared to the high growth rates presented in Fig. 7. Additionally, there is no visible difference in $\mathrm{GR}_{\text {neg }}, \mathrm{GR}_{\text {pos }}$ and $\mathrm{GR}_{\mathrm{t}}$. They exhibit similar values throughout the whole growth process (cf. Table 2). Typically, $2 \mathrm{~nm}$ positive and negative ions show an earlier appearance $(\Delta t)$ of about 15 and $10 \mathrm{~min}$, respectively (Fig. 8c, d). The decrease of $\Delta t$ during the growth process is relatively slow. Nevertheless, the diameter at which $\Delta t$ approaches zero is still at about $20 \mathrm{~nm}$. The time needed for the total particle mode to grow to this size is approximately $200 \mathrm{~min}$ (Fig. 8b). The time difference deduced from $D p_{\max }$ becomes negative at a diameter of about $20 \mathrm{~nm}$, supporting the assumption that growth rates above this diameter are overestimated. As $\Delta t$ shows a slow decrease during the growth process, $\mathrm{GR}_{\mathrm{t}}$ should be slightly enhanced compared to $\mathrm{GR}_{\text {neg }}$ and $\mathrm{GR}_{\text {pos }}$. This is not visible in our data. Presumably, the accuracy of the applied growth rate determination is not sufficient to resolve such slight differences.

As the absolute contribution of ion-ion recombination and ion-particle attachment to NPF is not quantitatively assessed in this work we propose a conceptual mechanism governing our observations. Figure 9 shows the conceptual model for interactions of positive cluster ions (red) with the negative growing ion mode (blue), the neutral background particles and the neutral growing mode (both black). For illustrational 

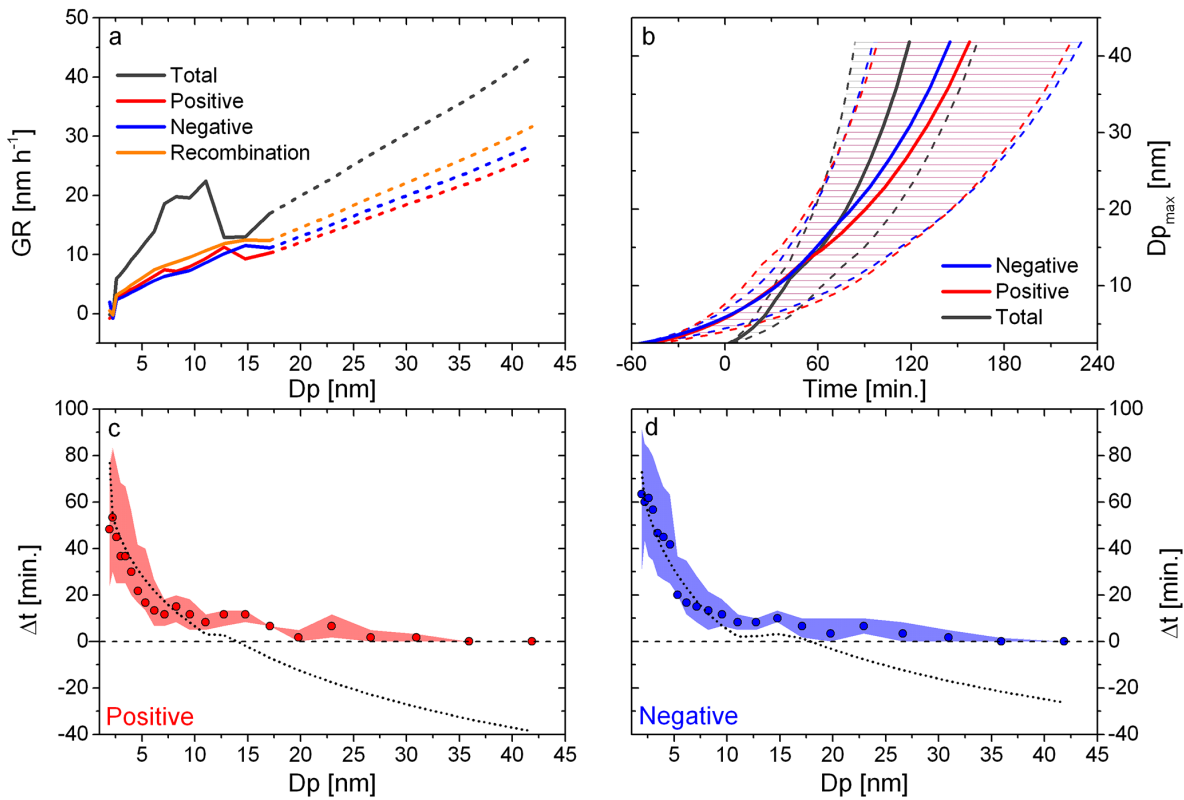

Figure 7. Median evolution of ions and particles for four NPF events with $\Delta t>20 \mathrm{~min}$. (a) GR for total, positive, negative and recombined particles. (b) Time evolution of the growing modes $\left(D p_{\max }\right)$ of negative, positive and total particles, respectively. Hatched areas denote the 25th and 75th percentiles. (c, d) Time difference $(\Delta t)$ for negative and positive ions, respectively. Dotted black lines are time differences calculated from the negative and positive growing mode to the total one, in principle this is the difference between the three $D p_{\text {max }}$-values from section $b)$.
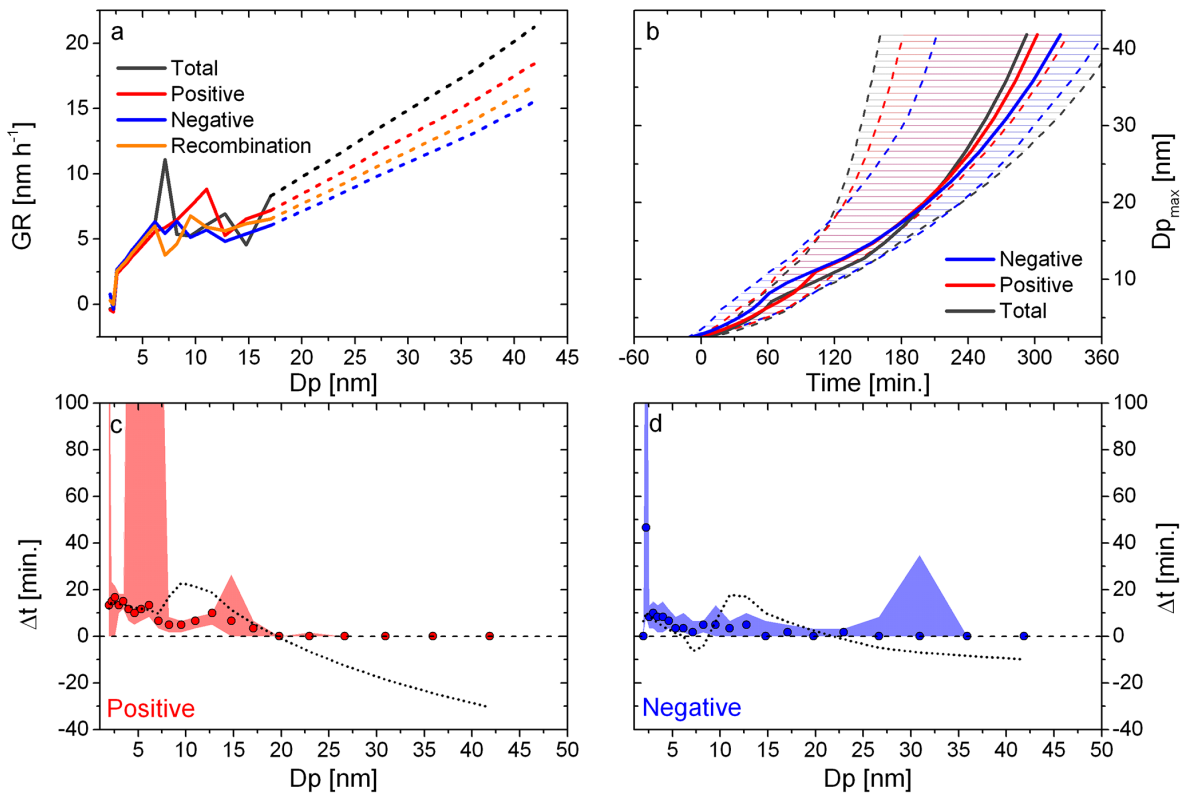

Figure 8. Same as Fig. 7 but for four NPF events with $\Delta t<20 \mathrm{~min}$.

purposes, we will focus on the ion attachment (green dashed lines) and the recombination of cluster ions with the growing ion mode (yellow dashed lines) and neglect the recombination of cluster ions with each other.

At the onset of NPF (Fig. 9a), first particles are formed in the ion fraction, exhibiting concentrations in the order of
$10^{1} \mathrm{~cm}^{-3}$. Ion-ion recombination occurs among cluster ions and the freshly nucleated ion mode (yellow dashed line). Additionally, the background aerosol particles, exhibiting concentrations in the order of $10^{3} \mathrm{~cm}^{-3}$, are available for the attachment of cluster ions (green dashed line). Considering the recombination coefficient $\alpha$ at $2 \mathrm{~nm}$ and the attachment 


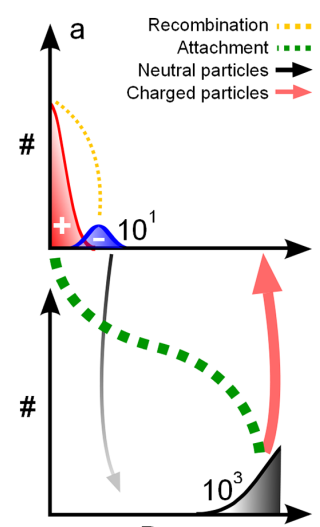

$\mathrm{Dp}$

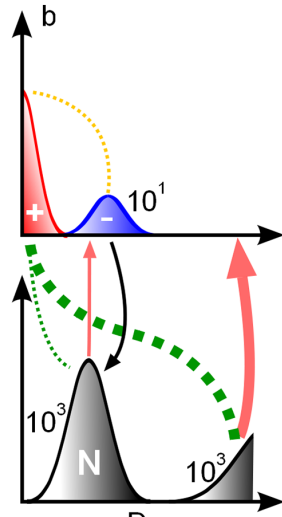

$\mathrm{Dp}$

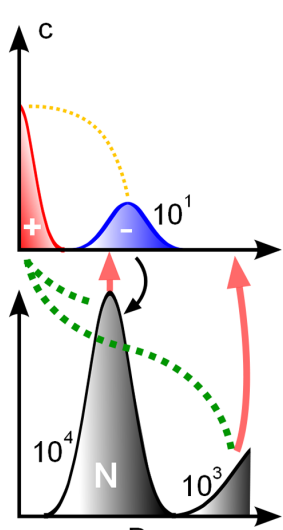

$\mathrm{Dp}$

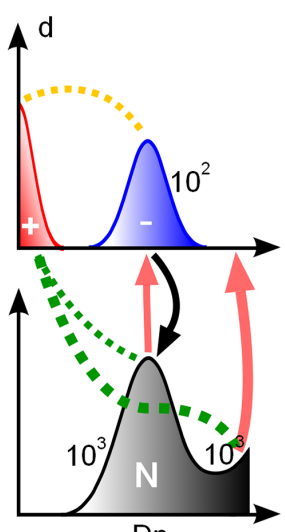

$\mathrm{Dp}$

Figure 9. Conceptual model of the influence of cluster ion recombination and attachment at different stages of particle nucleation and growth (a-d). Permanently available positive cluster ions are denoted in red, the negative growing mode in blue and neutral particle modes in black. The black and red arrows denote the generation of neutral and charged particles, respectively. The size of the arrows and dashed lines denotes the prevailing mechanism. Numerals indicate the orders of magnitude of the number concentrations of the respective modes.

coefficient $\beta$ at $100 \mathrm{~nm}$ (cf. Fig. 1, yellow and green solid lines), the probabilities for cluster ions to interact with the growing ion mode and with the neutral background particles are approximately the same. As the background aerosol is more numerous than the freshly nucleated ion mode, attachment to the background particles dominates over recombination. Hence, only a very small number of neutral particles are formed by recombination.

Once precursor gas phase components are available in a sufficient quantity for neutral nucleation (cf. Almeida et al., 2013; Kulmala et al., 2013; Schobesberger et al., 2013), a strong nucleation burst of neutral particles occurs (Fig. 9b). The freshly nucleated neutral mode has a very small mean diameter (e.g., 1.5-2 nm) and shows typical concentrations in the order of $10^{3} \mathrm{~cm}^{-3}$. The background particle number size distribution stays mostly unchanged $(D p>100 \mathrm{~nm}$; $10^{3} \mathrm{~cm}^{-3}$ ). Now, the neutral nucleation mode and the background particles are available for the attachment of cluster ions. Meanwhile, the ion mode has grown to a greater diameter (e.g., $4 \mathrm{~nm}$ ), exhibiting only a slightly enhanced number concentration still in the order of $10^{1} \mathrm{~cm}^{-3} . \beta$ for cluster ion attachment to the background particles is elevated by 2 orders of magnitude compared to the neutral nucleation mode (cf. Fig. 1). Therefore, cluster ion attachment to the background particles dominates over the attachment to the neutral nucleation mode, as both modes have similar concentrations. On the other hand, $\alpha$ for cluster ions with the growing ion mode is elevated by 2 orders of magnitude compared to $\beta$ for the neutral growing mode. As the neutral mode exhibits approximately 2 orders of magnitude more particles, the absolute number of cluster ions recombining with the ion mode is comparable to the number of ions attaching to the neutral mode. In other words, background particles are charged strongly (bold red arrow), the neutral nucleation mode experiences moderate charging (red arrow), and the formation of neutral particles by recombination is also moderate (black arrow). This moderate formation of somewhat greater neutral particles from recombination contributes to the growth of the neutral mode. On the other hand, the ions formed by attachment to the neutral mode are somewhat smaller than the mean ion mode diameter, and contribute to a slower growth of the ion mode. The absolute production of neutral and charged particles by this mechanism depends on the concentration of cluster ions as well as on the concentration of the growing ion- and neutral modes, and is thought to be in the order of $0.01 \mathrm{~cm}^{-3} \mathrm{~s}^{-1}$.

As the growth continues, the neutral particle mode reaches a number concentration peak (order of $10^{4} \mathrm{~cm}^{-3}$ ) at diameters of approximately 4-5 nm (Fig. 9c). Due to the high concentration, the attachment probability of cluster ions to the neutral nucleation mode and the background particles is similar (green dashed lines). Meanwhile, the ion mode has grown further (e.g., $6 \mathrm{~nm}$ diameter), and is slightly more numerous but still in the order of $10^{1} \mathrm{~cm}^{-3}$. Therefore, recombination is somewhat enhanced compared to stage (b). Nevertheless, the neutral nucleation mode experiences a stronger loss of particles due to attachment of cluster ions. As a result, the concentration of the growing ion mode is further enhanced by the addition of somewhat smaller charged particles. Again, the loss of ions (due to recombination) and the addition of newly formed smaller ions (due to attachment) results in an apparent growth rate reduction of the ion mode. On the other hand, the concentration of the neutral mode is constantly reduced, while its growth rate stays elevated.

Finally, the diameters of the neutral and ion growing modes approach each other (Fig. 9d). By this time the concentration of the ion mode is further enhanced $\left(10^{2} \mathrm{~cm}^{-3}\right)$ and the neutral mode concentration has decreased to about $10^{3} \mathrm{~cm}^{-3}$. The converging concentrations and similar diameters result in a comparable magnitude of attachment and 
recombination to the ion and neutral growing modes. As the neutral particles (formed from recombination) and the charged particles (formed from attachment) have approximately the same diameter, an enhancement or slowing of the growth rates is not expected. This results in an equilibrium state where ions and neutral particles grow at similar rates.

\section{Conclusions}

Data from 8 NPF events measured with the NAIS at the Waldstein site showed an earlier appearance of the ion modes in the beginning of NPF and a higher initial growth rate of the delayed total particle mode in comparison to the ion modes. The enhanced growth of the total particle mode does eventually result in the disappearance of the ion's advance. To our knowledge, such differences of ion and total growth rates in the initial stages of cluster growth have not been presented before. Therefore, it is an interesting yet open question if these observations are just a special feature of the Waldstein site, or if they can also be found elsewhere. An earlier appearance of the ion mode is plausible, as ions reduce the critical cluster size and facilitate the cluster activation (e.g., Lushnikov and Kulmala, 2004; Winkler et al., 2008; Yu and Turco, 2000; Yue and Chan, 1979). To, at least partly, explain the difference in the growth rates we have proposed a mechanism including ion-ion recombination and ion-particle attachment (cf. Fig. 9).
Due to limitations of our measurement equipment (detection limit for neutral particles $\sim 2 \mathrm{~nm}$ ), no direct conclusions on the influence of ions on neutral particle nucleation can be deduced at the size range where the onset of NPF occurs. As stated by Kontkanen et al. (2013) and Kulmala et al. (2013), pure cluster ion recombination is not thought to be of sufficient magnitude to explain the intense neutral nucleation bursts. Further, Manninen et al. (2010) reported that ion-induced nucleation does only contribute about $10-13 \%$ to NPF. Nevertheless, ion interactions may play an important role in NPF by simultaneously enhancing the neutral particle growth rate and reducing the ion growth rate. However, the proposed mechanism is only valid in environments where the ionization rate $(Q)$ is strong enough to provide sufficient cluster ions for recombination and attachment. 


\section{Appendix A}

According to Tammet and Kulmala (2005), the size dependent coagulation coefficient $\mathrm{K}_{i j}$ is defined as

$K_{i j}=\frac{2 \pi k T\left(B_{i}+B_{j}\right)\left(D_{i}+D_{j}+2 h\right)}{1+\gamma-\frac{0.299 \gamma}{\gamma^{1.1}+0.64}+\gamma \frac{1-p}{p}}$,

where

$\gamma=2 \frac{B_{i}+B_{j}}{D_{i}+D_{j}+2 h} \sqrt{\frac{2 \pi k T m_{i} m_{j}}{m_{i}+m_{j}}}$.

Here, $k$ is the Boltzmann constant $\left[1.38 \times 10^{-23} J \mathrm{~K}^{-1}\right], T$ is the absolute temperature $[\mathrm{K}], B$ is the particle's mechanic mobility $\left[\mathrm{m} \mathrm{N}^{-1} \mathrm{~s}^{-1}\right.$ ] (Hinds, 1999), $D$ is the particle diameter $[\mathrm{m}]$, the sticking probability $p$ was assumed to be one, and $\mathrm{m}$ is the mass of an individual particle [kg]. To account for van der Waals interactions, an extra distance $h=$ $0.115 \times 10^{-9} \mathrm{~m}$ is necessary (Tammet and Kulmala, 2005). The variability of the size-dependent coagulation coefficient due to a $20 \%$ change in $B$, a doubling and a reduction to $50 \%$ of $h$ and the variation of $p$ between 0.5 and 1 is depicted as shaded areas in Fig. 1. The sticking probability exhibits the most pronounced influence on the values of $K_{i j}$, while the other two variables only show a minor effect.

An approximation for the size dependent attachment coefficient $\beta_{i j}$ is given by Hõrrak et al. (2008):

$\beta_{i j}=\frac{2 \pi D_{i} k T Z_{j}}{e} \frac{x}{\exp (x)-1}$
$\sqrt{1-\frac{2}{2+n(n-1)+D_{i} /(10 \mathrm{~nm})}}$,

where,

$x=\frac{n e^{2}}{2 \pi D_{i} \varepsilon_{0} k T}$.

Here, $Z$ is the electric mobility of the ion provided by the NAIS $\left[\mathrm{m}^{2} \mathrm{~V}^{-1} \mathrm{~s}^{-1}\right], e$ is the elementary electric charge $\left[1.6 \times 10^{-19} \mathrm{C}\right], n$ is the number of elementary charges carried by a charged particle, and $\varepsilon_{0}$ is the electric constant $\left[8.85 \times 10^{-12} \mathrm{~F} \mathrm{~m}^{-1}\right]$. The variability of $\beta_{i j}$ was assessed by varying $Z$ in the range of the bin width of the respective NAIS size channel (cf. Fig. 1).
For the interaction of oppositely charged ions of size $j$ and $k$, a size dependent recombination coefficient $\alpha$ can be described by the attachment coefficient $\beta_{i j}$ (Hoppel and Frick, 1986). Therefore, the recombination coefficient $\left(\alpha_{j k}\right)$ is defined equally to the attachment coefficient, but only for oppositely charged ions:

$\alpha_{j k}=\beta_{j k}$.

The coagulation sink is calculated according to Kulmala et al. (2012):

$\operatorname{CoagS}_{i}=\sum_{l=i}^{l=\max } K_{i l} N_{l}$,

where $N_{l}$ is the number concentration of the background aerosol $\left[\mathrm{cm}^{-3}\right]$ in the size class $l$.

The calculation of the charging sink follows Eq. (3) from Hõrrak et al. (2008):

$\operatorname{CharS}_{i}^{ \pm}=p_{i} \sum_{j} \beta_{i j} N_{j}^{ \pm}$,

where, $p_{i}$ is the probability of a neutral particle in size class $i$ to carry one elementary charge and $N_{j}^{ \pm}$is the number concentration of positive or negative ions in size class $j\left[\mathrm{~cm}^{-3}\right]$.

Hoppel and Frick (1986) proposed a simplified balance equation for the cluster ion production rate. For our work, we use a slightly altered version, not assuming symmetric concentrations of positive and negative small ions and considering size-dependent attachment and recombination coefficients. The balance equation for the ionization rate $Q^{ \pm}$is defined as:

$\frac{\mathrm{d} N_{<1.6 \mathrm{~nm}}^{ \pm}}{\mathrm{d} t}=Q^{ \pm}-\sum_{j k} \alpha_{j k} N_{j}^{+} N_{\mathrm{k}}^{-}-\sum_{i j} \beta_{i j} p_{i} N_{i} N_{j}^{ \pm}$,

where size classes $j$ and $k<1.6 \mathrm{~nm}, N_{j}^{+}$and $N_{k}^{-}$are positive and negative ion concentrations in size class $j$ and $k\left[\mathrm{~cm}^{-3}\right]$, $N_{i}$ is the concentration of neutral particles in size class $i$ $\left[\mathrm{cm}^{-3}\right]$ and $N_{<1.6 \mathrm{~nm}}^{ \pm}$is the number concentration of positive or negative ions with a diameter below $1.6 \mathrm{~nm}\left[\mathrm{~cm}^{-3}\right]$.

Acknowledgements. This work was funded by the German Research Foundation grant DFG HE5214/3-1. The authors gratefully acknowledge Xuemeng Chen, Stephanie Gagné and Sander Mirme for helpful advice and discussions.

Edited by: F. Yu 


\section{References}

Asmi, E., Sipilä, M., Manninen, H. E., Vanhanen, J., Lehtipalo, K., Gagné, S., Neitola, K., Mirme, A., Mirme, S., Tamm, E., Uin, J., Komsaare, K., Attoui, M., and Kulmala, M.: Results of the first air ion spectrometer calibration and intercomparison workshop, Atmos. Chem. Phys., 9, 141-154, doi:10.5194/acp-9-141-2009, 2009.

Almeida, J., Schobesberger, S., Kürten, A., Ortega, I. K., Kupiainen-Määttä, O., Praplan, A. P., Adamov, A., Amorim, A., Bianchi, F., Breitenlechner, M., David, A., Dommen, J., Donahue, N. M., Downard, A., Dunne, E., Duplissy, J., Ehrhart, S., Flagan, R. C., Franchin, A., Guida, R., Hakala, J., Hansel, A., Heinritzi, M., Henschel, H., Jokinen, T., Junninen, H., Kajos, M., Kangasluoma, J., Keskinen, H., Kupc, A., Kurtén, T., Kvashin, A. N., Laaksonen, A., Lehtipalo, K., Leiminger, M., Leppä, J., Loukonen, V., Makhmutov, V., Mathot, S., McGrath, M. J., Nieminen, T., Olenius, T., Onnela, A., Petäjä, T., Riccobono, F., Riipinen, I., Rissanen, M., Rondo, L., Ruuskanen, T., Santos, F. D., Sarnela, N., Schallhart, S., Schnitzhofer, R., Seinfeld, J. H., Simon, M., Sipilä, M., Stozhkov, Y., Stratmann, F., Tomé, A., Tröstl, J., Tsagkogeorgas, G., Vaattovaara, P., Viisanen, Y., Virtanen, A., Vrtala, A., Wagner, P. E., Weingartner, E., Wex, H., Williamson, C., Wimmer, D., Ye, P., Yli-Juuti, T., Carslaw, K. S., Kulmala, M., Curtius, J., Baltensperger, U., Worsnop, D. R., Vehkamäki, H., and Kirkby, J.: Molecular understanding of sulphuric acid-amine particle nucleation in the atmosphere, Nature, 502, 359-363, doi:10.1038/nature12663, 2013.

Enghoff, M. B. and Svensmark, H.: The role of atmospheric ions in aerosol nucleation - a review, Atmos. Chem. Phys., 8, 49114923, doi:10.5194/acp-8-4911-2008, 2008.

Fuchs, N. A.: On the stationary charge distribution on aerosol particles in a bipolar ionic atmosphere, Geofis. Pura E Appl., 56, 185-193, doi:10.1007/BF01993343, 1963.

Gagné, S., Nieminen, T., Kurtén, T., Manninen, H. E., Petäjä, T., Laakso, L., Kerminen, V.-M., Boy, M., and Kulmala, M.: Factors influencing the contribution of ion-induced nucleation in a boreal forest, Finland, Atmos. Chem. Phys., 10, 3743-3757, doi:10.5194/acp-10-3743-2010, 2010.

Gagné, S., Lehtipalo, K., Manninen, H. E., Nieminen, T., Schobesberger, S., Franchin, A., Yli-Juuti, T., Boulon, J., Sonntag, A., Mirme, S., Mirme, A., Hõrrak, U., Petäjä, T., Asmi, E., and Kulmala, M.: Intercomparison of air ion spectrometers: an evaluation of results in varying conditions, Atmos. Meas. Tech., 4, 805-822, doi:10.5194/amt-4-805-2011, 2011.

Held, A., Nowak, A., Birmili, W., Wiedensohler, A., Forkel, R., and Klemm, O.: Observations of particle formation and growth in a mountainous forest region in central Europe, J. Geophys. Res., 109, D23204, doi:10.1029/2004JD005346, 2004.

Hinds, W. C.: Aerosol technology: properties, behavior, and measurement of airborne particles, Wiley, New York, 1999.

Hirsikko, A., Nieminen, T., Gagné, S., Lehtipalo, K., Manninen, H. E., Ehn, M., Hõrrak, U., Kerminen, V.-M., Laakso, L., McMurry, P. H., Mirme, A., Mirme, S., Petäjä, T., Tammet, H., Vakkari, V., Vana, M., and Kulmala, M.: Atmospheric ions and nucleation: a review of observations, Atmos. Chem. Phys., 11, 767-798, doi:10.5194/acp-11-767-2011, 2011.

Hoppel, W. A. and Frick, G. M.: Ion-aerosol attachment coefficients and the steady-state charge distribution on aerosols in a bipolar ion environment, Aerosol Sci. Tech., 5, 1-21, doi:10.1080/02786828608959073, 1986.

Hoppel, W. A. and Frick, G. M.: The nonequilibrium character of the aerosol charge distributions produced by neutralizes, Aerosol Sci. Tech., 12, 471-496, doi:10.1080/02786829008959363, 1990.

Hõrrak, U., Aalto, P. P., Salm, J., Komsaare, K., Tammet, H., Mäkelä, J. M., Laakso, L., and Kulmala, M.: Variation and balance of positive air ion concentrations in a boreal forest, Atmos. Chem. Phys., 8, 655-675, doi:10.5194/acp-8-655-2008, 2008.

Iida, K., Stolzenburg, M., McMurry, P., Dunn, M. J., Smith, J. N., Eisele, F., and Keady, P.: Contribution of ion-induced nucleation to new particle formation: methodology and its application to atmospheric observations in Boulder, Colorado, J. Geophys. Res., 111, D23201, doi:10.1029/2006JD007167, 2006.

Kemski, J., Siehl, A., Stegemann, R., and Valdivia-Manchego, M.: Mapping the geogenic radon potential in Germany, Sci. Total Environ., 272, 217-230, doi:10.1016/S0048-9697(01)00696-9, 2001.

Kontkanen, J., Lehtinen, K. E. J., Nieminen, T., Manninen, H. E., Lehtipalo, K., Kerminen, V.-M., and Kulmala, M.: Estimating the contribution of ion-ion recombination to sub-2 $\mathrm{nm}$ cluster concentrations from atmospheric measurements, Atmos. Chem. Phys., 13, 11391-11401, doi:10.5194/acp-13-11391-2013, 2013.

Kulmala, M. and Kerminen, V.-M.: On the formation and growth of atmospheric nanoparticles, Atmos. Res., 90, 132-150, doi:10.1016/j.atmosres.2008.01.005, 2008.

Kulmala, M., Vehkamäki, H., Petäjä, T., Dal Maso, M., Lauri, A., Kerminen, V.-M., Birmili, W., and McMurry, P. H.: Formation and growth rates of ultrafine atmospheric particles: a review of observations, J. Aerosol Sci., 35, 143-176, doi:10.1016/j.jaerosci.2003.10.003, 2004a.

Kulmala, M., Laakso, L., Lehtinen, K. E. J., Riipinen, I., Dal Maso, M., Anttila, T., Kerminen, V.-M., Hõrrak, U., Vana, M., and Tammet, H.: Initial steps of aerosol growth, Atmos. Chem. Phys., 4, 2553-2560, doi:10.5194/acp-4-2553-2004, 2004b.

Kulmala, M., Petäjä, T., Nieminen, T., Sipilä, M., Manninen, H. E., Lehtipalo, K., Dal Maso, M., Aalto, P. P., Junninen, H., Paasonen, P., Riipinen, I., Lehtinen, K. E. J., Laaksonen, A., and Kerminen, V.-M.: Measurement of the nucleation of atmospheric aerosol particles, Nat. Protoc., 7, 1651-1667, doi:10.1038/nprot.2012.091, 2012.

Kulmala, M., Kontkanen, J., Junninen, H., Lehtipalo, K., Manninen, H. E., Nieminen, T., Petaja, T., Sipila, M., Schobesberger, S., Rantala, P., Franchin, A., Jokinen, T., Jarvinen, E., Aijala, M., Kangasluoma, J., Hakala, J., Aalto, P. P., Paasonen, P., Mikkila, J., Vanhanen, J., Aalto, J., Hakola, H., Makkonen, U., Ruuskanen, T., Mauldin, R. L., Duplissy, J., Vehkamaki, H., Back, J., Kortelainen, A., Riipinen, I., Kurten, T., Johnston, M. V., Smith, J. N., Ehn, M., Mentel, T. F., Lehtinen, K. E. J., Laaksonen, A., Kerminen, V.-M., and Worsnop, D. R.: Direct observations of atmospheric aerosol nucleation, Science, 339, 943-946, doi:10.1126/science.1227385, 2013.

Laakso, L., Gagné, S., Petäjä, T., Hirsikko, A., Aalto, P. P., Kulmala, M., and Kerminen, V.-M.: Detecting charging state of ultrafine particles: instrumental development and ambient measure- 
ments, Atmos. Chem. Phys., 7, 1333-1345, doi:10.5194/acp-71333-2007, 2007.

Leppä, J., Anttila, T., Kerminen, V.-M., Kulmala, M., and Lehtinen, K. E. J.: Atmospheric new particle formation: real and apparent growth of neutral and charged particles, Atmos. Chem. Phys., 11, 4939-4955, doi:10.5194/acp-11-4939-2011, 2011.

Lüers, J., Smaczny, J., Kies, A., and Bareiss, J.: Dynamik der Austauschprozesse von $\mathrm{CO}_{2}$ und Radon zwischen Waldboden, Waldbestand und Atmosphäre, Berichte Meteorol. Institutes Uiversität Freiburg, 16, 147-52, 2007.

Lushnikov, A. A. and Kulmala, M.: Charging of aerosol particles in the near free-molecule regime, Eur. Phys. J.-Atmos. Mol. Opt. Plasma Phys., 29, 345-355, doi:10.1140/epjd/e2004-000479, 2004.

Makkonen, R., Asmi, A., Kerminen, V.-M., Boy, M., Arneth, A., Hari, P., and Kulmala, M.: Air pollution control and decreasing new particle formation lead to strong climate warming, Atmos. Chem. Phys., 12, 1515-1524, doi:10.5194/acp-12-15152012, 2012.

Manninen, H. E., Nieminen, T., Riipinen, I., Yli-Juuti, T., Gagné, S., Asmi, E., Aalto, P. P., Petäjä, T., Kerminen, V.-M., and Kulmala, M.: Charged and total particle formation and growth rates during EUCAARI 2007 campaign in Hyytiälä, Atmos. Chem. Phys., 9, 4077-4089, doi:10.5194/acp-9-4077-2009, 2009a.

Manninen, H. E., Petaja, T., Asmi, E., Riipinen, I., Nieminen, T., Mikkila, J., Horrak, U., Mirme, A., Mirme, S., Laakso, L., Kerminen, V.-M., and Kulmala, M.: Long-term field measurements of charged and neutral clusters using Neutral cluster and Air Ion Spectrometer (NAIS), Boreal Environ. Res., 14, 591-605, $2009 \mathrm{~b}$.

Manninen, H. E., Nieminen, T., Asmi, E., Gagné, S., Häkkinen, S., Lehtipalo, K., Aalto, P., Vana, M., Mirme, A., Mirme, S., Hõrrak, U., Plass-Dülmer, C., Stange, G., Kiss, G., Hoffer, A., Törö, N., Moerman, M., Henzing, B., de Leeuw, G., Brinkenberg, M., Kouvarakis, G. N., Bougiatioti, A., Mihalopoulos, N., O’Dowd, C., Ceburnis, D., Arneth, A., Svenningsson, B., Swietlicki, E., Tarozzi, L., Decesari, S., Facchini, M. C., Birmili, W., Sonntag, A., Wiedensohler, A., Boulon, J., Sellegri, K., Laj, P., Gysel, M., Bukowiecki, N., Weingartner, E., Wehrle, G., Laaksonen, A., Hamed, A., Joutsensaari, J., Petäjä, T., Kerminen, V.-M., and Kulmala, M.: EUCAARI ion spectrometer measurements at 12 European sites - analysis of new particle formation events, Atmos. Chem. Phys., 10, 7907-7927, doi:10.5194/acp-10-79072010, 2010.

Manninen, H. E., Franchin, A., Schobesberger, S., Hirsikko, A., Hakala, J., Skromulis, A., Kangasluoma, J., Ehn, M., Junninen, H., Mirme, A., Mirme, S., Sipilä, M., Petäjä, T., Worsnop, D. R., and Kulmala, M.: Characterisation of coronagenerated ions used in a Neutral cluster and Air Ion Spectrometer (NAIS), Atmos. Meas. Tech., 4, 2767-2776, doi:10.5194/amt-42767-2011, 2011.

Merikanto, J., Spracklen, D. V., Mann, G. W., Pickering, S. J., and Carslaw, K. S.: Impact of nucleation on global CCN, Atmos. Chem. Phys., 9, 8601-8616, doi:10.5194/acp-9-8601-2009, 2009.

Mirme, S. and Mirme, A.: The mathematical principles and design of the NAIS - a spectrometer for the measurement of cluster ion and nanometer aerosol size distributions, Atmos. Meas. Tech., 6, 1061-1071, doi:10.5194/amt-6-1061-2013, 2013.
Reischl, G. P., Mäkelä, J. M., Karch, R., and Necid, J.: Bipolar charging of ultrafine particles in the size range below $10 \mathrm{~nm}, \mathrm{~J}$. Aerosol Sci., 27, 931-949, doi:10.1016/0021-8502(96)00026-2, 1996.

Savitzky, A. and Golay, M. J.: Smoothing and Differentiation of Data by Simplified Least Squares Procedures, Anal. Chem., 36, 1627, 1964.

Schobesberger, S., Junninen, H., Bianchi, F., Lönn, G., Ehn, M., Lehtipalo, K., Dommen, J., Ehrhart, S., Ortega, I. K., Franchin, A., Nieminen, T., Riccobono, F., Hutterli, M., Duplissy, J., Almeida, J., Amorim, A., Breitenlechner, M., Downard, A. J., Dunne, E. M., Flagan, R. C., Kajos, M., Keskinen, H., Kirkby, J., Kupc, A., Kürten, A., Kurtén, T., Laaksonen, A., Mathot, S., Onnela, A., Praplan, A. P., Rondo, L., Santos, F. D., Schallhart, S., Schnitzhofer, R., Sipilä, M., Tomé, A., Tsagkogeorgas, G., Vehkamäki, H., Wimmer, D., Baltensperger, U., Carslaw, K. S., Curtius, J., Hansel, A., Petäjä, T., Kulmala, M., Donahue, N. M., and Worsnop, D. R.: Molecular understanding of atmospheric particle formation from sulfuric acid and large oxidized organic molecules, P. Natl. Acad. Sci. USA, 110, 17223-17228, doi:10.1073/pnas.1306973110, 2013.

Spracklen, D. V., Carslaw, K. S., Kulmala, M., Kerminen, V.-M., Mann, G. W., and Sihto, S.-L.: The contribution of boundary layer nucleation events to total particle concentrations on regional and global scales, Atmos. Chem. Phys., 6, 5631-5648, doi:10.5194/acp-6-5631-2006, 2006.

Tammet, H. and Kulmala, M.: Simulation tool for atmospheric aerosol nucleation bursts, J. Aerosol Sci., 36, 173-196, doi:10.1016/j.jaerosci.2004.08.004, 2005.

Tammet, H., Hõrrak, U., and Kulmala, M.: Negatively charged nanoparticles produced by splashing of water, Atmos. Chem. Phys., 9, 357-367, doi:10.5194/acp-9-357-2009, 2009.

Virkkula, A., Hirsikko, A., Vana, M., Aalto, P. P., Hillamo, R., and Kulmala, M.: Charged particle size distributions and analysis of particle formation events at the Finnish Antarctic research station Aboa, Boreal Environ. Res., 12, 397-408, 2007.

Wiedensohler, A.: An approximation of the bipolar charge distribution for particles in the submicron size range, J. Aerosol Sci., 19, 387-389, doi:10.1016/0021-8502(88)90278-9, 1988.

Wiedensohler, A., Birmili, W., Nowak, A., Sonntag, A., Weinhold, K., Merkel, M., Wehner, B., Tuch, T., Pfeifer, S., Fiebig, M., Fjäraa, A. M., Asmi, E., Sellegri, K., Depuy, R., Venzac, H., Villani, P., Laj, P., Aalto, P., Ogren, J. A., Swietlicki, E., Williams, P., Roldin, P., Quincey, P., Hüglin, C., FierzSchmidhauser, R., Gysel, M., Weingartner, E., Riccobono, F., Santos, S., Grüning, C., Faloon, K., Beddows, D., Harrison, R., Monahan, C., Jennings, S. G., O’Dowd, C. D., Marinoni, A., Horn, H.-G., Keck, L., Jiang, J., Scheckman, J., McMurry, P. H., Deng, Z., Zhao, C. S., Moerman, M., Henzing, B., de Leeuw, G., Löschau, G., and Bastian, S.: Mobility particle size spectrometers: harmonization of technical standards and data structure to facilitate high quality long-term observations of atmospheric particle number size distributions, Atmos. Meas. Tech., 5, 657-685, doi:10.5194/amt-5-657-2012, 2012.

Winkler, P. M., Steiner, G., Vrtala, A., Vehkamaki, H., Noppel, M., Lehtinen, K. E. J., Reischl, G. P., Wagner, P. E., and Kulmala, M.: Heterogeneous nucleation experiments bridging the scale from molecular ion clusters to nanoparticles, Science, 319, 13741377, doi:10.1126/science.1149034, 2008. 
Yli-Juuti, T., Nieminen, T., Hirsikko, A., Aalto, P. P., Asmi, E., Hõrrak, U., Manninen, H. E., Patokoski, J., Dal Maso, M., Petäjä, T., Rinne, J., Kulmala, M., and Riipinen, I.: Growth rates of nucleation mode particles in Hyytiälä during 20032009: variation with particle size, season, data analysis method and ambient conditions, Atmos. Chem. Phys., 11, 12865-12886, doi:10.5194/acp-11-12865-2011, 2011.

Yu, F.: From molecular clusters to nanoparticles: second-generation ion-mediated nucleation model, Atmos. Chem. Phys., 6, 51935211, doi:10.5194/acp-6-5193-2006, 2006.

Yu, F. and Turco, R. P.: Ultrafine aerosol formation via ion-mediated nucleation, Geophys. Res. Lett., 27, 883-886, doi:10.1029/1999GL011151, 2000.
Yu, F. and Turco, R. P.: Case studies of particle formation events observed in boreal forests: implications for nucleation mechanisms, Atmos. Chem. Phys., 8, 6085-6102, doi:10.5194/acp-86085-2008, 2008.

Yu, F. and Turco, R. P.: The size-dependent charge fraction of sub-3$\mathrm{nm}$ particles as a key diagnostic of competitive nucleation mechanisms under atmospheric conditions, Atmos. Chem. Phys., 11, 9451-9463, doi:10.5194/acp-11-9451-2011, 2011.

Yue, G. K. and Chan, L..: Theory of the formation of aerosols of volatile binary solutions through the ion-induced nucleation process, J. Colloid Interf. Sci., 68, 501-507, doi:10.1016/00219797(79)90308-4, 1979. 